\title{
A IMPORTÂNCIA DA EDUCAÇÃO FÍSICA NA VISÃO DOS ALUNOS DE UMA ESCOLA PÚBLICA
}

Paulo Ricardo Brasilio GOZI ${ }^{\mathbf{1}}$

Faculdade Estácio de Sá de Ourinhos (FAESO)

João Carlos Pereira de MORAES ${ }^{2}$

Faculdade Estácio de Sá de Ourinhos (FAESO)

Resumo: Este trabalho tem por objetivo analisar a percepção dos alunos em relação ao interesse pelas aulas de Educação Física de uma escola pública no interior do estado do Paraná. Para tanto, foi realizado um questionário com 15 questões e aplicado a 39 estudantes de ambos os sexos de uma escola pública localizada na cidade em questão. Como resultado, percebem-se aulas com atividades repetitivas, alunos poucos motivados para participação nas aulas práticas e, mesmo assim, uma escola bem preparada em sua infraestrutura para as atividades. Por fim, evidencia-se a ausência de um projeto comum para a atuação docente em Educação Física que motivasse e possibilitasse aos sujeitos se aproximar e participar ativamente das aulas da disciplina.

Palavras-chave: Educação Física. Escola Pública. Percepção de alunos.

\begin{abstract}
This work aims to analyze the students' perception regarding the interest in the Physical Education classes of a public school and with this raise possible resolutions for these problems in order to provide classes with quality and interest and participation of the students. For that, a questionnaire with 15 questions was applied and applied to 39 students of both sexes of a public school located in a city in the interior of the parana. As a result, one can see repetitive activities, students with little motivation to participate in practical classes, and yet a well-prepared school in their infrastructure for activities. It is evidenced the absence of a common project for the teaching activity in Physical education that motivated and enabled the subjects to approach and participate actively in the classes of the discipline.
\end{abstract}

Keywords: Physical Education. Public school. Perception of students.

\footnotetext{
${ }^{1}$ Graduação e Educação Física pela Sociedade de Ensino Superior Estácio de Sá - Ourinhos.

${ }^{2}$ Doutor em Educação pela Universidade de São Paulo-USP. Professor da Faculdade Estácio de Sá de Ourinhos (FAESO). E-mail: joaocarlos_pmoraes@yahoo.com.br.
} 


\section{Introdução}

A partir da promulgação da Lei de Diretrizes e Bases da Educação Nacional 9394 de 1996 - LDB (BRASIL, 1996), a Educação Física passou a ser um componente curricular como qualquer outro, trazendo consigo uma série de mudanças, relacionadas à estrutura didática e à autonomia dada às escolas e aos sistemas de ensino, e ainda o enfoque dado à formação do cidadão.

Além da LDB, outro documento que regulamenta a Educação Física são os Parâmetros Curriculares Nacionais - PCN (BRASIL, 1998). De acordo com os PCNs, o ensino médio é a etapa que encerra a educação básica e tem por finalidade consolidar os conhecimentos adquiridos no Ensino Fundamental por meio da construção de competências básicas que situem o aluno como produtor de conhecimento e cidadão participante.

A Educação Física, para ser conhecida como um componente curricular tão importante quanto os outros, deve apresentar objetivos claros e com um corpo de conhecimentos específicos e organizados, cuja aprendizagem possa colaborar para que os objetivos da educação escolar sejam alcançados (BRASIL, 1998).

Atualmente, entende-se a Educação Física na escola como uma área que trata da cultura corporal de movimento e que tem por finalidade introduzir e integrar o aluno nessa esfera, formando um cidadão que vai produzi-la e também transforma-la (MORAES; ALVES, 2018). Por meio da realização de estágios em diversas escolas, foram observados que inúmeros alunos tanto do ensino fundamental, quanto do ensino médio, perderam o interesse pelas aulas de Educação Física.

Isso, na nossa concepção, deve-se a falta de empenho dos professores em mediar o ensino de conteúdo da aula de maneira que consiga despertar interesse dos discentes para participar das aulas e adquirir conhecimento teórico e prático. Contudo, Soares (1996, p.6-12) afirma que:

[...] a aula de educação física é um lugar de aprender coisas e não apenas o lugar onde aqueles que dominam técnicas rudimentares de um determinado esporte vão "praticar" o que já sabem, enquanto aqueles que não sabem continuam no mesmo lugar.

Nesse sentido, concordamos também com Freire (1996, p. 25) quando diz que “[...] ensinar não é transferir conhecimento, mas criar as possibilidades para a sua produção ou a sua construção". Assim, ensinar aos discentes a verdadeira educação física 
vai muito além de se praticar um esporte que você já sabe jogar, é desenvolver habilidades, adquirir conhecimentos, técnicas, coordenação motora etc.

Contudo, Darido (2010, p.14) afirma:

O fato é que muitos profissionais se apegam a estes tipos de atividades e deixam de lado o interesse por aulas diversificadas trabalhando assim o conteúdo programado, ocasionando o famoso professor(a) "rola bola".

Por outro lado, Barbosa e Freitas (1996) ressalta que a Educação Física deve assumir o compromisso em desencadear uma educação corporal sobre o movimento, conhecendo e levando em consideração o contexto no qual o aluno está inserido. Com isso os adolescentes passam a ter possíveis entendimentos sobre a realidade.

No ensino médio, observamos que, enquanto componente curricular, a Educação Física contribui para mudanças e transformações no plano individual e coletivo do aluno (BRASIL, 1998). As aulas devem ser dinâmicas, estimulantes e interessantes, nas quais haja uma relação complexa entre a teoria e a prática na metodologia de ensino.

A educação física escolar, segundo a LDB n 9.394/96 (BRASIL, 1996), tem como finalidade para o ensino médio consolidar e aprofundar os conhecimentos adquiridos no Ensino Fundamental, também possibilitando o prosseguimento dos estudos, o preparo para o trabalho e cidadania, e desenvolvimento de habilidades.

O ensino médio compreende uma etapa importante para a formação dos alunos, na qual se busca, através de metodologias diversificadas, compreensão, aprofundamento e discussão dos componentes trabalhados durante a formação no ensino fundamental (BRASIL, 1998). Portanto, o professor deve assegurar ao educando uma forma crítica, capaz de levá-lo a refletir sobre temáticas cotidianas e interferir positivamente em seu meio.

Verderi (1998) mostra a importância da Educação Física em todos os níveis de ensino, indicando que ela deverá promover sociabilização e a inserção de todos os alunos nas práticas corporais, com intuito de valorizar, apreciar e desfrutar dos benefícios proporcionados pela cultura de movimento. Sendo assim, o objetivo deste trabalho será analisar a percepção dos alunos em relação ao interesse pelas aulas de Educação Física de uma escola pública.

\section{Materiais e métodos}


Trata-se de uma pesquisa de campo do tipo transversal, caracterizando-se como de natureza quantitativa.

\section{Amostra}

A amostra foi constituída por 39 estudantes de ambos os sexos, abrangendo uma faixa etária entre 15 e 17 anos de idade, sendo alunos do ensino médio de uma escola pública, localizada numa cidade do interior do estado do Paraná.

\section{Instrumentos}

Para a coleta de dados foi aplicado um questionário contendo 15 questões, o qual consiste em perguntas objetivas de múltipla escolha, com possibilidades para dissertar e demonstrar opiniões. As perguntas referem-se à importância das aulas de Educação Física na etapa de Educação Básica que frequentam. Em alguns momentos, ainda, a pesquisa foi apoiada em falas soltas de alunos na realização do questionário e/ou em observações parciais do pesquisador sobre a escola.

\section{Procedimentos}

Para a obtenção dos dados desta pesquisa foi solicitado autorização da direção escolar. A diretora da escola auxiliou na aplicação dos questionários, informando aos pais uma semana antes de sua aplicação, a fim de esclarecê-los sobre os objetivos da pesquisa e obter a autorização para a participação dos filhos no preenchimento do questionário. $\mathrm{O}$ tempo para responder as questões foi de 30 minutos e foi aplicado em sala de aula pelo pesquisador, que acompanhou e realizou a leitura em voz alta das questões para todos, bem como sanou dúvidas que surgiram no momento.

\section{Análise dos dados}

O tratamento e as análises de dados foram feitos por técnicas estatísticas, utilizando a representação por gráficos e uso de porcentagem. Para a apresentação e discussão, a análise apoiou-se nas seguintes categorias: Caracterização do Grupo; Aulas em si; O professor da disciplina de Educação Física; e A escola.

\section{Resultados e discussões}

A seguir são apresentados os dados, dividindo-os nas categorias apresentadas anteriormente:

\section{Categoria A: Caracterização do Grupo}

Sobre a caracterização do grupo fora realizado duas questões, que suscitaram os gráficos abaixo: 


\section{Como você classifica a cor de sua pele de acordo com as categorias do IBGE?}

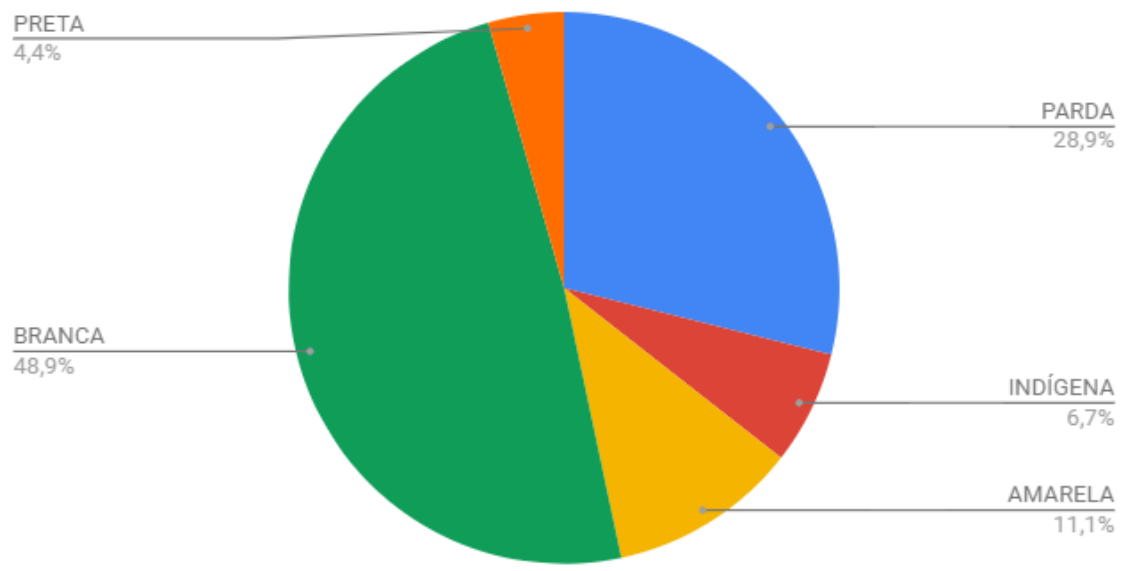

Figura 1. Demonstração De Resultados da classificação de cor de pele dos alunos.

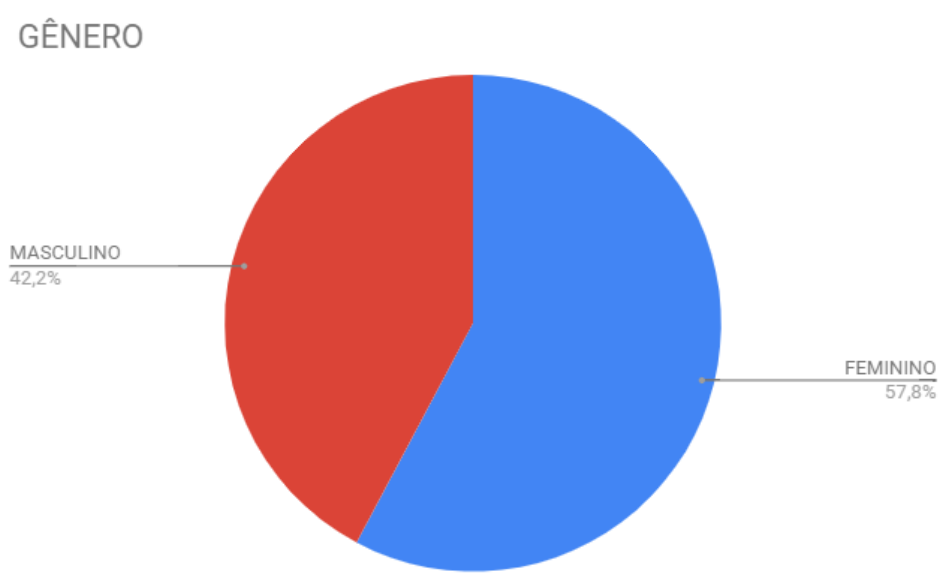

Figura 2. Resultado referente ao gênero dos alunos da classe onde foi realizada a pesquisa.

De acordo com o primeiro gráfico, figura 1, a maioria dos sujeitos da pesquisa se denomina da cor branca, sendo que a minoria considera-se de cor preta ${ }^{3}$. Já quanto ao gênero, o segundo gráfico, representado pela figura 2, demonstra uma maioria de alunos do gênero feminino, sendo 26 meninas $(42,2 \%)$ e 19 meninos (57,8\%). Esses dados representam certa fidedignidade da proporção de gênero da população do Sul do Brasil, região esta de realização da pesquisa. De acordo com o Instituto Brasileiro de Geografia e Estatística (IBGE, 2013), no Sul encontram-se, em porcentagem, 47,9\% homens e $52,1 \%$ mulheres para a faixa etária de 14 a 17 anos.

\section{Categoria B: Alunos}

Nessa categoria privilegiaram-se interesse, adaptação e repetição das aulas.

Quanto ao interesse, foi possível elaborar o seguinte gráfico:

\footnotetext{
${ }^{3}$ Os dados acima coletados são a declaração dos sujeitos e não se refere necessariamente a sua real cor. MARGENS - Revista Interdisciplinar 


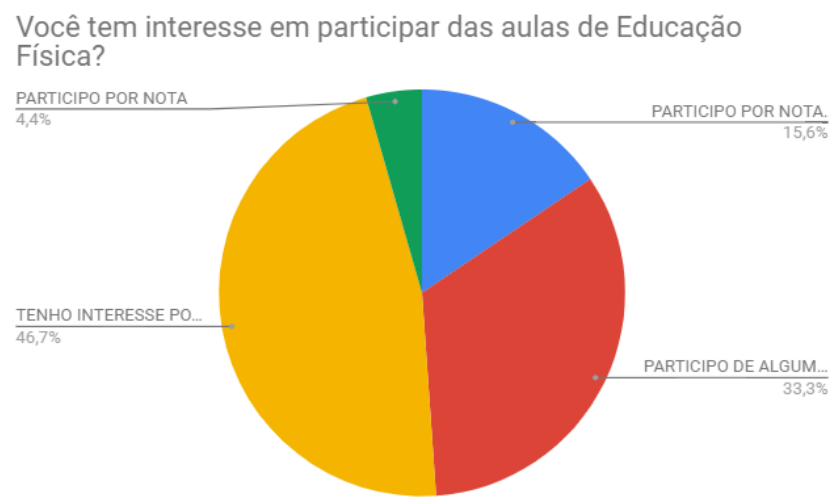

Figura 3. Demonstra o nível de interesse dos alunos nas aulas de Educação Física.

Podemos ver no gráfico acima que a maioria dos alunos diz ter interesse em participar das atividades ministradas pelo professor (46,7\%), entretanto, esclareceram que falta atividades diversificadas nas aulas, como observaremos mais a fundo na questão 5. Uma boa parte dos alunos respondeu que participa de algumas aulas e não de todas $(33,3 \%)$, pelo fato de serem repetitivas e não haver novidades ou outros aprendizados ofertados pelo professor.

Outros alunos ressaltam que somente participa das atividades que o professor avisa que valerá nota $(15,6 \%)$. Alguns ainda argumentaram que pelo fato de terem aula nos próximos horários em sala de aula, fazer as atividades físicas os deixariam "sujos" para prosseguir o dia e, por isso, não realizam as atividades. Essa afirmação é confirmada nas seguintes falas:

A escola precisa de vestiários com chuveiros para podermos tomar banho após as atividades desenvolvidas para que possamos prosseguir o dia sem quaisquer desconfortos (SUJEITO 1).

Teríamos que obter uniformes específicos para a aula prática de Educação Física caso não seja possível um vestiário, não resolveria o problema mais já ajudaria bastante na continuação das aulas (SUJEITO 2).

No que se refere à adaptação das aulas, construiu-se o seguinte gráfico: 


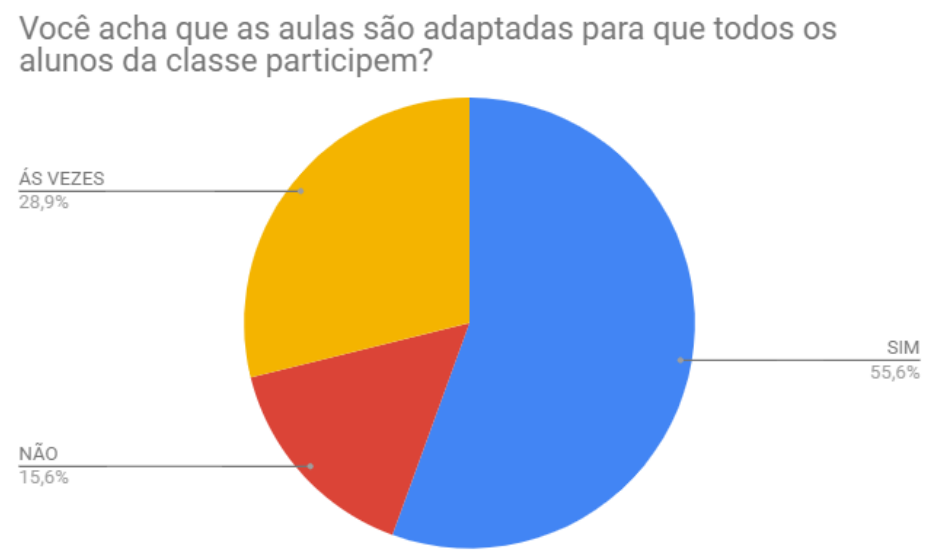

Figura 4. Demonstra o grau de adaptação das aulas para todos os membros da classe

Nesse sentido, conforme a visão dos alunos percebe-se que a maioria das aulas é adaptada para todos os alunos da classe $(55,6 \%)$, no entanto, o conceito de adaptação, conforme Sassaki (1997), não permite deixar de lado nenhum aluno. Ou seja, só consideraríamos adaptação se esta ocorresse plenamente para todo grupo, totalizando $100 \%$. Sobre essa questão, observa-se o seguinte relato:

Ao longo da pesquisa, participei de uma aula prática onde consegui observar que alguns alunos tiveram dificuldade de entender a atividade ministrada pelo professor, e acabaram por não questionar o professor e tirar suas dúvidas sobre a atividade, talvez por receio de sofrer algum tipo de preconceito por parte dos colegas de classe ou por falta de interesse (RELATO DO PESQUISADOR).

Sobre aulas repetitivas, consolidaram-se as seguintes porcentagens:

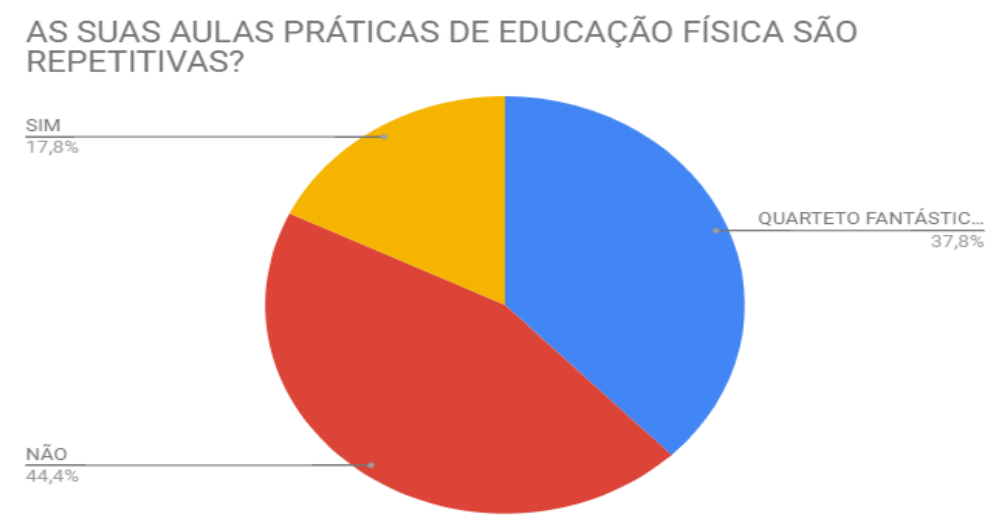

Figura 5. Demonstração do nível de repetições das aulas práticas

O gráfico acima evidencia que 44,4\% dos alunos alegam que as aulas práticas não são repetitivas, que são ministradas atividades diversificadas (resposta de vinte alunos). 37,8\% dos alunos concordaram com a opção "quarteto fantástico" (Futebol, Queimada, Futsal e Vôlei) como padrão de aula, algo possível pelo apego dos alunos ou do professor 
por tais atividades (respostas de dezessete alunos). Já 17,8\% dos alunos afirmaram que as aulas práticas são repetitivas, porém não especificaram quais atividades são ministradas.

Analisando a questão das aulas de Educação Física e os níveis de satisfação dos alunos, podemos observar que as aulas da disciplina de certa forma são repetitivas e parcialmente adaptadas, conforme aponta Folle e Teixeira (2012). O que acaba gerando certo desconforto nos alunos que querem atividades diversificadas e inclusivas.

Nesse sentido, consideramos pertinente a importância da Educação Física nas escolas como espaços de adaptação e inclusão escolar (CASTRO; 2005). Fazem-se necessárias, ainda, escolas com estruturas prontas para receber os professores e seus alunos independentes de suas dificuldades, tanto motora quanto psicológica, professores capacitados para realizar as atividades com seus alunos de forma clara, objetiva e coesa.

\section{Categoria C: O Professor de Educação Física}

Nessa categoria privilegiaram-se compreensão e participação de atividades. Quanto à compreensão das atividades, foi possível elaborar o seguinte gráfico:

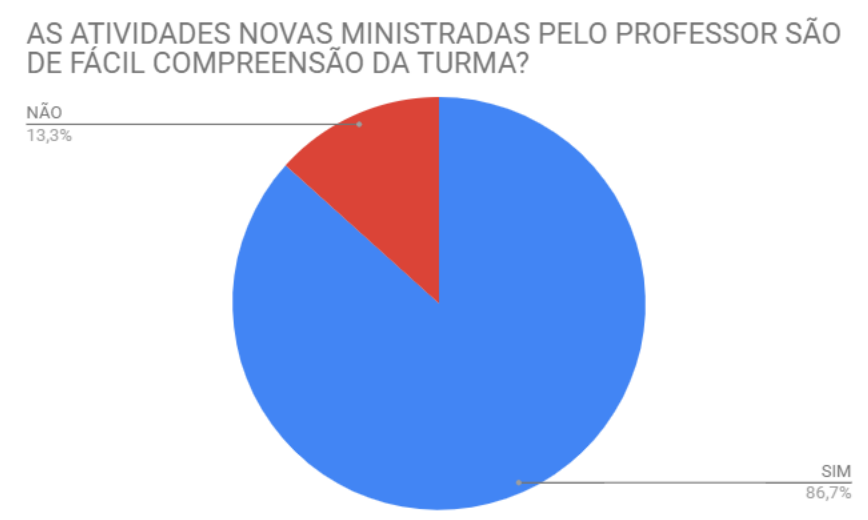

Figura 6. Nível de compreensão dos alunos sobre as atividades ministradas

Muitos alunos alegaram que o professor de Educação Física da escola é bem claro e objetivo na hora de explicar as atividades $(86,7 \%)$.

Questionados sobre essa clareza e objetividade do professor a grande parte dos alunos informou que é fácil entender as atividades por que na maioria das aulas é a mesma atividade que o professor passa, já que no paraná os professores não têm uma cartilha para ser seguida, então os alunos ficam repetindo atividades até que o professor desenvolva atividades novas. (Relato do pesquisador).

A ideia apresentada acima retrata novamente a questão da repetição das atividades propostas pelo professor de Educação Física, o que torna mais fácil dos alunos aprenderem as atividades, pois, elas são aplicadas no cotidiano das aulas práticas. Mas, 
por outro lado, inibe o desenvolvimento de novas atividades que poderiam ser aplicadas e desenvolvidas pelo professor.

No que se refere à participação nas aulas práticas, os alunos responderam:

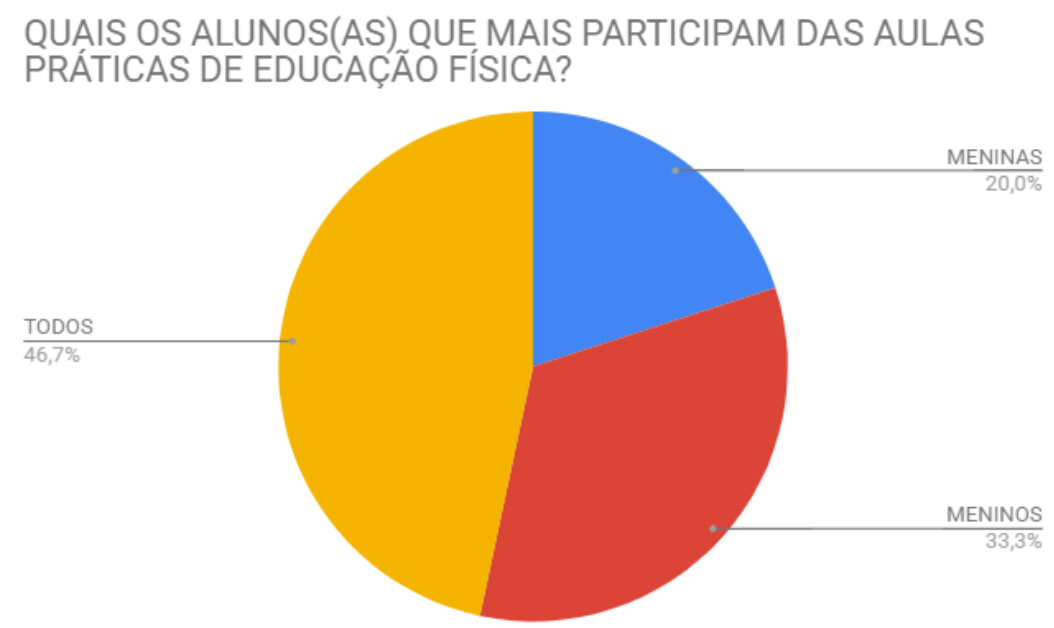

Figura 7. Grau de Alunos que participam das aulas práticas

Pode-se perceber que os alunos que participaram da pesquisa, em sua maioria, alegam que todos participam das atividades quando são atividades diversificadas. O que deixa claro que, quando são atividades novas, as quais os alunos não conhecem ainda, a classe inteira participa pelo interesse em aprender algo novo, de participar de uma atividade nova que ainda não compreendem.

Isso potencializa a prática docente, uma vez que os alunos têm interesse em participar das aulas, mesmo que seja somente por atividades diferentes das que já estão acostumados, pois, no tempo moderno em que vivemos hoje, entre celulares, jogos etc. (BIANCHI; PIRES; VANZIN, 2009), ainda há crianças e adolescentes interessados em aprender atividades ministradas pelo professor.

Nota-se ainda uma diferenciação na participação quanto ao gênero. Percebe-se que meninos $(33,3 \%)$ participam mais ativamente das práticas de Educação Física do que meninas $(20,0 \%)$. Sobre as atividades que mais participam, nota-se o seguinte: 


\section{QUAIS AS ATIVIDADES QUE VOCÊ MAIS PARTICIPA NAS AULAS DE EDUCAÇÃO FISICA?}

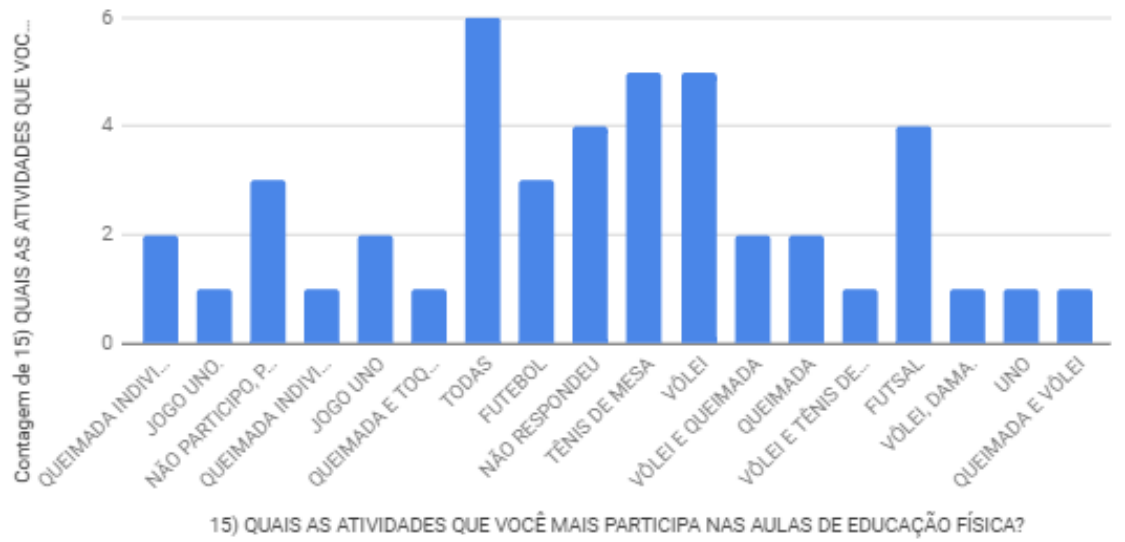

Figura 8. Atividades mais realizadas pelos alunos da classe

Na figura acima, podemos perceber que os alunos optam por queimada, vôlei, futsal, baralho, algo que já se tornou rotina nas aulas de Educação Física do grupo. Destacamos, ainda, entre os elementos interessantes, a polaridade entre o não participar (3 alunos) e não responderam (4 alunos), com vôlei (5 alunos), tênis de mesa (5 alunos) e futsal (4 alunos). Dito isso, vê-se que há uma dissonância de não participação e desinteresse e uma apropriação dos esportes mais cotidianos numa prática repetitiva docente.

Analisando a questão do professor de Educação Física, notamos que ele é pouco reflexivo sobre suas práticas, repetindo modelos de ação de sua própria escolarização. Segundo Schön (2000), o professor necessita superar modelos pré-prontos de aulas com o intuito de atingir uma prática de reflexão sobre a ação, tanto no seu contexto de atuação como após a mesma. Isso se torna evidente no grau de participação dos alunos da classe que transparecem práticas sexistas, muitas vezes provenientes do modelo militar de escolarização (OLIVEIRA, 2004).

\section{Categoria D: A escola}

Nessa categoria, privilegiaram-se espaço físico e materiais da escola para realização de atividades.

Quanto ao espaço físico da escola, foi possível elaborar o seguinte gráfico: 


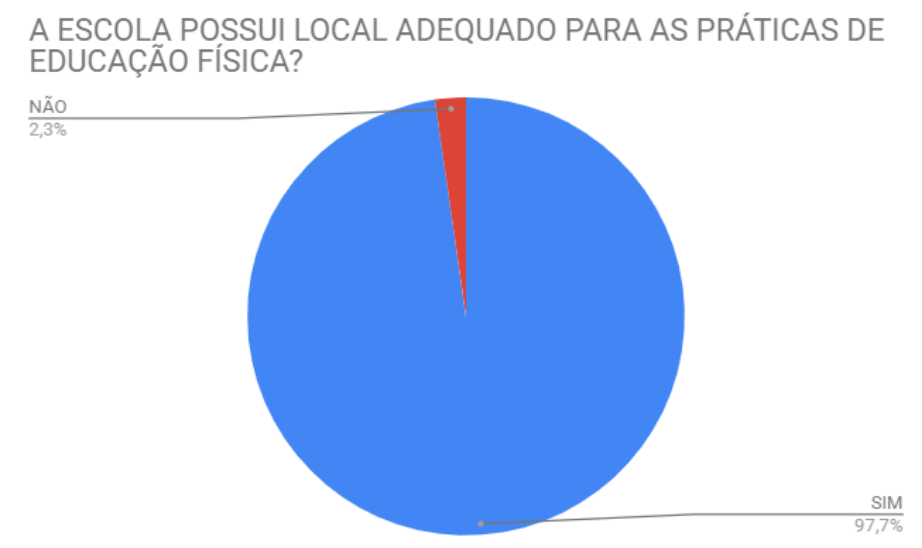

Figura 9. Nível do local adequado para as aulas práticas

Nessa figura, podemos ver que a escola onde foi realizada a pesquisa é uma escola bem preparada estruturalmente para que os professores possam realizar as atividades, até pelo fato de possuir vasto acervo de materiais para serem usados nas aulas práticas $(97,7 \%)$. Quanto ao resultado negativo sobre o local adequado das aulas, o aluno, em sua resposta, informou que faltam ainda algumas coisas para a escola estar totalmente completa, como melhoria na quadra de basquete e também na pista de atletismo $(2,3 \%)$.

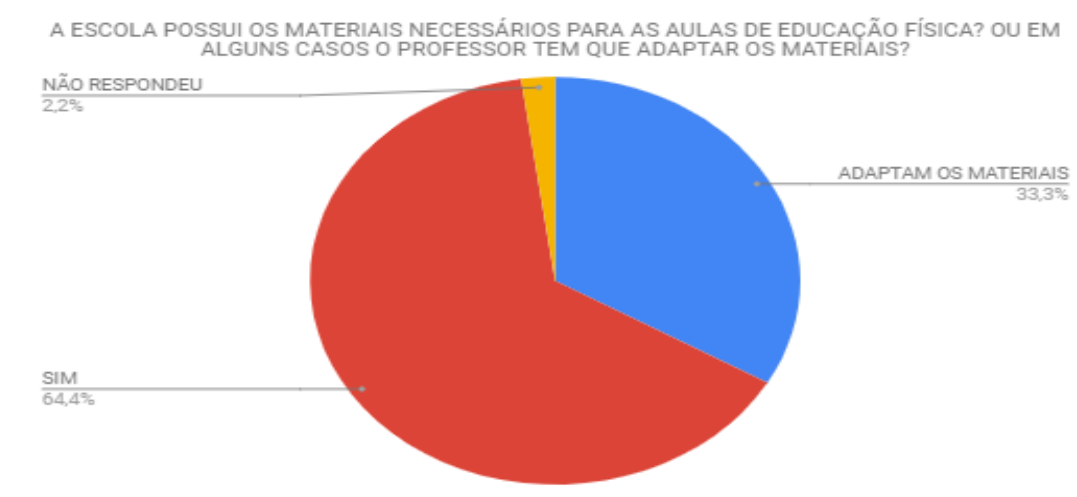

Figura 10. Demonstra se a escola possui os materiais para as aulas práticas ou se é necessário adaptação pelo professor.

Pode-se perceber que a escola possui os materiais necessários para o desenvolvimento das atividades que o professor possa ensinar $(64,4 \%)$. Os alunos ressaltaram que a escola gasta com materiais para as aulas de Educação Física, mas eles são guardados e quase nunca usados. Os professores preferem adaptar a aula com os materiais antigos do que usar o novo, não se sabe ao certo o motivo disso acontecer.

Entretanto é algo a se levar em conta uma vez que os materiais são comprados para serem usados com os alunos, conversando com uma professora antiga na escola ela me disse que não há necessidade de usar materiais novos para as mesmas atividades todo santo dia, então só se usa os materiais novos em novas atividades ministradas pelo professor (Relato do Pesquisador). 
A escola, diferente da maioria da realidade brasileira, possui, na visão dos alunos, os materiais necessários para a prática das atividades, no entanto, o seu uso é questionável frente a pouca variedade oferecida pelos professores de Educação Física.

\section{Conclusão}

Conforme os resultados dessa pesquisa pode-se concluir que grande parte dos entrevistados demonstra insatisfação pela ausência atividades diversificadas, atividades que os alunos ainda não conhecem, fato este que o professor de Educação Física da escola deverá levar em conta para as próximas aulas. Tais achados sugerem que há necessidade de intervenção nas aulas práticas do professor, a fim de orientá-lo sobre a necessidade de levar algo novo para os seus alunos. Há também a necessidade de maiores motivações para professores antigos na escola que acabam usando o quarteto fantástico como base para todas as suas aulas.

Mesmo frente a essa realidade percebemos que a escola é bem estruturada e bem equipada para as aulas práticas dos alunos, entretanto, sentiu-se a ausência de um projeto comum para a atuação docente em Educação Física que motivasse e possibilitasse aos sujeitos se aproximar e participar ativamente das aulas da disciplina.

\section{Referências}

BARBOSA, F. A. S.; FREITAS, F.J.C. A Didática e sua Contribuição no Processo de Formação do Professor. $\quad$ Disponível em: 〈http://fapb.edu.br/media/files/35/35_1939.pdf>. Acesso em: 25/06/2018.

BIANCHI, P.; PIRES, G.L; VANZIN, T. As Tecnologias de Informação e Comunicação na Rede Municipal de Ensino de Florianópolis: possibilidades para a educação (física). Revista Linhas, v. 9, n. 2, 2009.

BRASIL. Parâmetros Curriculares Nacionais: Educação Física. Brasília: $\quad$ Secretaria de Educação Fundamental,MEC/SEF, 1998.

BRASIL. Lei no. 9.394, de 20 de dezembro de 1996. Estabelece as Diretrizes e Bases da educação nacional. Legislação, Brasília, DF, dez. 1996. Disponível em: <http:// www.mec.gov.br/sef/fundef/Ftp/leg/lein9394.doc>

CASTRO, E. M. Atividade física adaptada. Novo Conceito, 2005.

DARIDO, S. C. Para ensinar Educação Física: Possibilidades de intervenção na escola. 6.ed. Campinas - SP: Editora Papirus, 2010. 
FOLLE, A.; TEIXEIRA, F.A. Motivação de escolares das séries finais do Ensino Fundamental nas aulas de Educação Física. Journal of Physical Education, v. 23, n. 1, p. 37-44, 2012.

FREIRE, P. Pedagogia da autonomia: saberes necessários à prática educativa. São Paulo: Paz e Terra, 1996. Disponível em:< http://forumeja.org.br/files/Autonomia.pdf>. Acesso em: 01/06/2018.

IBGE, Diretoria de Pesquisas, Coordenação de Trabalho e Rendimento, Pesquisa Nacional por Amostra de Domicílios Contínua, 2013.

MORAES, J. C. P; GUILHERME, V.A. A Base Nacional Curricular ComumDocumento Preliminar (BNCC)... Com A Palavra, Os Especialistas! Ciência \& Desenvolvimento-Revista Eletrônica da FAINOR, v. 11, n. 1, 2018.

OLIVEIRA, M. A. T. Educação física escolar e ditadura militar no Brasil (1968-1984): entre a adesão e a resistência. Revista Brasileira de Ciências do Esporte, v. 25, n. 2, 2004.

SASSAKI, R. K. Inclusão - construindo uma sociedade para todos. Rio de Janeiro: WVA Editora, 1997.

SCHÖN, D. Educando o profissional reflexivo: um novo design para o ensino e a aprendizagem. Porto Alegre: Artes Médicas, 2000.

SOARES, C. L. Educação Física escolar: Conhecimento e especificidade. Disponível em: <https://www.revistas.usp.br/rpef/article/view/139637/134931>. Acesso em: 01/06/2018.

VERDERI, E. A dança na escola. Rio de Janeiro: Sprint 1998. 